\title{
Use of Multiple Representations in Understanding Addition: The Case of Pre-school Children
}

\author{
Kamariah Abu Bakar, Suziyani Mohamed, \\ Faridah Yunus and Aidah Abdul Karim \\ Universiti Kebangsaan Malaysia \\ Bangi, Selangor
}

\begin{abstract}
An important objective in mathematics education is to ensure learners' comprehension of the subject through effective teaching and learning, as emphasized by many countries worldwide, such as the United States, Australia, Singapore, and Malaysia in terms of the organization of mathematics and its curriculum documents. This paper explores young children's (6 years old) use of multiple representations in understanding the concept of addition during problem-solving activities. The study employed a case study research design, comprising two young children in one preschool centre. Data collection included observation, dialogue with the children, and an analysis of various creations and usage of representation that shed light into both children's capacity in utilizing different representation forms and performing translations. The findings unveiled the children's capability in using a variety of representation forms, and performing translations within, and between different representation forms (with prompting). This study discusses the importance of facilitating the early development of young children's use of multiple representations and performing translations to support their deep comprehension of the concept of addition.
\end{abstract}

Keywords: addition; multiple representations; problem-solving; understanding; young children

\section{Introduction}

Representation is vital in mathematics classrooms of all grade levels, in both teaching and learning. Mathematics teachers worldwide introduce a variety of representation forms during instruction, which may include concrete materials, visual images, i.e. pictures and photographs, written, and spoken symbols (Bakar \& Karim, 2019; Elia, Gagatsis \& Demetriou, 2007; Rosli, Goldsby \& Capraro, 2015). Meanwhile, students create different representation forms to help them access ideas in mathematics, present their thinking, and find solutions. Past researches

*Corresponding author: Kamariah Abu Bakar, Email: kamariah_abubakar@ukm.edu.my 
have given emphasis to the benefits of using multiple representations (e.g. realworld situations, pictures, photographs, physical, verbal, and written symbols) for both the teaching and learning of mathematics, to ease the communication of mathematical ideas and thinking, to help understand concepts in mathematics, and to aid in problem-solving activities (Ahmad, Tarmizi \& Nawawi, 2010; Ayub, Ghazali \& Othman, 2013; Bakar \& Karim, 2019; Elia et al., 2007; Rosli, Goldsby \& Capraro, 2015). Despite the advantages of using multiple representations, as have been reported in previous studies, little is explored about young children's mathematical understanding, especially pertaining to the concept of addition. Additionally, little is known about young children's capability in performing translations within, and between different representation forms.

\section{Research Background}

Mathematics researchers emphasized the prominence of students' conceptual understanding in mathematics classrooms (Hiebert, 1997; NCTM, 2000). Teachers worldwide have employed various teaching practices including utilizing realistic mathematical education, multiple representation usage and integrating various technology devices in mathematics classrooms to enhance students' mathematical understanding (e.g. Bautista, Habib, Eng Bull, 2019; Kaur, Koval \& Chaney, 2017; Papadakis, Kalogiannakis \& Zaranis 2017; Ulusoy \& Incikabi, 2019). However, it is quite difficult to gauge how students gain conceptual understanding since this is not observable in a straightforward manner. Still, students' understanding could be inferred through various representations that they would produce during learning sessions. When students produce a variety of representations to solve tasks in hand, they simultaneously structure their ideas (Francis \& Tom, 2001). Representation refers to any configuration of signs, characters, or objects, which can also symbolize something else (Goldin, 1998). For example, photographs can represent events, numbers can exemplify quantities, and words can signify numerals. Mathematics researchers worldwide have highlighted the importance of representation, indicating its contribution to students' creation of mathematical thinking and ideas (Abdullah, Halim \& Zakaria, 2014; Abdullah, Zakaria \& Halim, 2012; Ainsworth, Bibby, \& Wood, 2002; Pape \& Tchoshanov, 2001; Yuanita, Zulnaidi, \& Zakaria, 2018). Representation is acknowledged as a tool for thinking and obtaining insights (Diezmann \& English, 2001). Comprehension and mathematical thinking can be communicated in many ways, such as in writing, in speech, in pictorial representations, and manipulative objects. Additionally, researchers have noted the high association between representation and comprehension, in which a student's level of understanding is linked to the types of representation utilized by that particular student (Mokwebu, 2013) and his/her capability to employ various representation modes. The Lesh Translation Model (Lesh et al.,1987) featured five representation modes that support learners' progress with mathematical concepts, namely:

1) real-world situations; comprising authentic real-life events;

2) manipulatives; denoting any concrete object that can be pointed to, touched, and moved;

3) pictures or diagrams; referring to imageries of mathematical ideas found anywhere, such as in textbooks and photographs; may also include children's selfgenerated drawings and photographs captured by them; 
4) spoken symbols; including formal spoken mathematical language/jargon and everyday language to clarify thinking, to respond to questions, and to explain;

5) written symbols; encompassing both mathematical symbols and the written words associated with them.

According to Suh, Johnston, Jamieson, and Mills (2008), the term "representational fluency" can be described as understanding intricately the capability to exemplify any mathematical thinking and idea in various forms, including the ability to make connections between various representations. The ability to utilize multiple representations and the capability to translate representational models have been proven to affect students' capabilities in developing mathematical ideas and thinking (Chigeza, 2013; Goldin \& Shteingold, 2001), as well as solving mathematics problems (Gagatsis \& Shiakalli, 2004).

Often times, a mathematics problem may require students to employ more than one representation form. Hence, it is beneficial that students are capable of utilizing multiple representations, together with the capacity to perform translation within, and between different representation forms, so that problems could be solved effectively (Lesh et al., 1987). Additionally, researchers highlighted the positive link between the use of multiple representations and translation ability, as both influence children's performance in problem-solving (Gagatsis \& Shiakalli, 2004; Lesh et al., 1987). To enable translation, learners should be able to connect one representation of a concept to another. They can begin with a representation that is most meaningful to them (e.g. concrete materials) and later switch to using others (e.g. symbols) to develop mathematical ideas. By performing more translations, more connections are achieved, that will subsequently form a "network of representations". The quality and quantity of linking different modes of representation will assist problem-solving processes. Hence, it is vital that teachers support students' capacities of switching between, and within different representation forms. Teachers should help students in exploring the use of multiple representations, and guide them in translating within, and between representations (Ballard, 2000). Furthermore, teachers should provide students with tasks that necessitate the usage of multiple representations, as such activities may afford students with frequent transitioning among different representations. The facility to do so contributes to the depth of students' comprehension and retention of mathematical concepts (Lesh et al., 1987).

Educators are concerned with the struggles encountered by preschool children in understanding the concept of addition; a more upsetting situation is that these children continue to experience difficulties in performing addition operations in the following year at primary school, i.e. in Year One (Tyng, Zaman, \& Ahmad, 2011). Hence, it is important to investigate whether using multiple representation and performing translation can help facilitate comprehension in the basic concept of addition in similar ways that older students understand other topics in mathematics. 


\section{The Study}

This study aims to explore children's usage of multiple representations during their attempt to solve problems with addition. Furthermore, this study investigates children's capacity in performing translation within, and between different representations. Specifically, this research addresses the following research questions:

1. How do young children use different forms of representation to exemplify the concept of addition?

2. In which ways, and to what extent do representations associate with children's understanding?

This study was conducted in a preschool center in Melaka, Malaysia. A focus group consisting of six children (aged six years old) from the same classroom was selected as this study's participants. Only six children were observed throughout the study, while the rest continued their lesson with the classroom teacher. These children who were selected as participants for this study were representative of different levels of mathematical achievement within the whole classroom. The selection of the children was in consultation with the teacher. However, for this particular paper, only the case of two children is presented as other children of the same range (the highest and lowest range) were observed to provide similar data. Aimy was selected as being representative of students from the low range while Norman from the high range. As this study was administered during the first term of school, the mathematics lessons and tasks at the time pertained to numbers and counting. For the first two months, the children had been introduced to numbers and had experienced counting various objects in their surroundings. They had not yet been introduced to the basics of mathematics operation.

For this study, the researcher played dual roles - as a researcher, and as a teacher to these children, by introducing the concept of addition through modeled situations, which required addition using concrete materials. This study is based on the constructivist theory of learning, which emphasizes student-centered learning by providing students with the opportunity to explore and experience a wide range of representations. Beginning with exploring addition using concrete materials, the researcher proceeded with the children's exploration of other forms of representation, including drawings and written symbols. Having had adequate exposure to addition processes and situations, the children were presented with the final problems, which required individual problem-solving using any form of representation. The problems requested the children to find the total number of legs for a small number of animals. However, the problems were mixed-level challenges, ranging from difficult to easy. Based on the pre-test scores, Norman, who had scored the highest, was given a challenging problem involving three addends (i.e. Problem A: 2 tigers and a chicken), whereas Aimy, who had scored the lowest, was asked to solve a simple problem with only two addends (Problem B: 2 tigers). 


\section{Methods}

Data collection consisted of observations, dialogues and conversations with the children, artifacts, field notes, and video recordings. The children's work including written symbols, drawings as well as constructions (using manipulatives) were photographed and saved on a computer. These artifacts were important evidence that supported classroom observations and conversations with the children. Video recordings of the children's engagement with the problem tasks enabled the children's verbal expressions and behaviors to be documented. The researcher had conversations/dialogues and asked the children several questions to get insights into what the children were doing and thinking. The collection of the children's artifacts comprising of various data sources including observations, conversations and video recordings, helps determine the type, quantity and quality of representations employed by the children and their flexibility in using multiple representations and translation among different representation forms.

The Lesh Translation Model (Lesh et al., 1987) was used as the analytical framework for the data analysis. Initially, conversations/dialogues with the children and observations were transcribed. Using the transcripts, artifacts, along with associated video recordings, the researcher coded the actions and verbalizations of the children into several categories: Manipulatives, Pictures, Verbal Symbols and Written Symbols. Additionally, video analysis of the children's attempting the tasks revealed the diverse methods of utilizing representations while attempting to complete the tasks. Conversations/dialogues with the children helped to clarify the representations that they had produced. Additionally, the children's talk assisted in explaining the thinking process involved for solving the problems. Themes common to all children were evaluated through a cross-analysis to understand the overall use of representations to facilitate understanding of mathematical concepts. Specifically, the researcher searched for common themes that were shared across children and differences unique to each child.

Next, these data were summarized and later organized in a table that displayed each child's pre-test score, representations, associated dialogues, and events, along with the children's behaviors that illustrated their thinking process. The table enabled a child's representations to be cross checked against several data sources, yielding a rich information about each child's representations. Additionally, the table allowed the researcher to compare the children's usage of representations and their associated thinking process.

\section{Findings and Discussion}

\section{How do young children use different forms of representation to exemplify the concept of addition?}

\section{Findings}

Aimy chose to draw as a means to solve Problem B (i.e. the total number of legs for two tigers). She first represented the legs of the animals with simple lines (Figure 1), then pointed to them as she counted each line until she reached the 
total number. Aimy demonstrated the counting action that she had performed earlier, indicating a dependence on her own creation of representation to solve the problem. Hence, Aimy's drawing was fundamental to her problem-solving strategy.

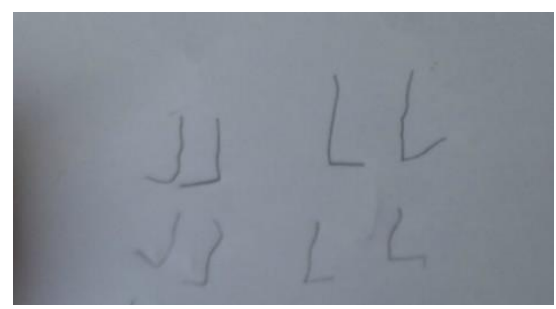

Figure 1: Aimy's drawings of the legs of 2 tigers

After having found the solution to the problem successfully, Aimy was then prompted by the researcher to make a translation into another form of representation. As can be seen in Figure 2, she chose to manipulate the coins available in front of her. She grabbed one coin at a time, placed them one by one on the table until she reached four (i.e. four legs for the first tiger). She continued with the same action to represent the legs for the second tiger. Finally, she pointed to each coin and counted them all; then with a smile, she affirmed ' 8 ' as the answer.

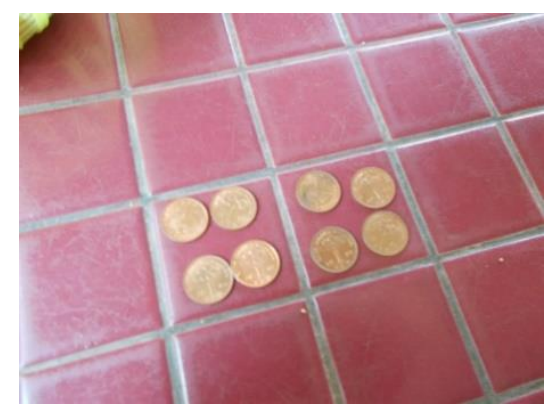

Figure 2: Aimy's representations of the legs of 2 tigers using coins

The researcher prompted Aimy again to make a translation into another representation form - symbols. She remained silent for some time but proceeded to look at her previous construction (i.e. coins). She counted the coins in each group before writing the corresponding numeral (i.e. 4), and then referred to her group of coins again before writing the second addend (i.e. 4). Cautiously, she counted all her coins together and wrote the total number (i.e. 8). When trying to include the addition symbol (i.e. ' + ' sign) into her number sentence (i.e. numerical expression/equation), she referred to the researcher and asked for assurance. Aimy successfully produced the correct number sentence (Figure 3).

$$
4+4=8
$$

Figure 3: Addition equation produced by Aimy

As for Norman, in his attempt to find the sum for the legs of 2 tigers and a chicken (Problem A), Norman had written the numeral ' 4 ' followed by ' 4 ' (as in Figure $4 a)$, but did not continue with the calculation as he realized the number sentence 
lacked the number of legs for the third animal. He then altered the numbers several times (see Figure $4 \mathrm{~b}$ ) by swapping between the numbers 2 and 4 (for the chicken's legs). Note that the equation still lacked the third addend. Despite the struggles in solving the problem, he still insisted on using symbols. He then decided to write the double numbers (' $4+4$ '), but without presenting the sum for all the animals' legs (Figure 4c).
a) $4+4$
b) $4+2$
c) $4+4=$

Figure 3: Norman's attempts using numerals and symbols to find the sum for three addends

Having noticed Norman's struggle using symbols, the researcher offered him to utilize other representation forms. As he realized that the use of symbols had not been effective for the current problem, he switched to using concrete materials provided on the table. He chose three pictures with the face of each animal type and attached the relevant number of pegs to correspond to the number of legs for two tigers and a chicken (Figure 5). Interestingly, he succeeded to gain the total. Joyfully, he answered 'ten', despite not finished attaching all the pegs. The fact that he did not count the pegs (that he had attached to the pictures of the animals' faces) but successfully figured out the total sum, suggests that he had applied the known double numbers $(4+4=8)$ and added 'two' to reach ten.

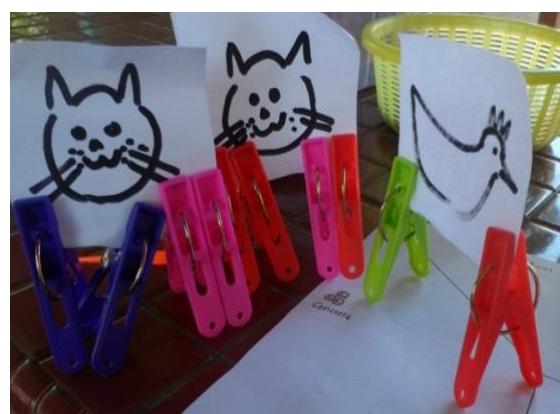

Figure 5: Norman's use of pegs to represent the number of legs for each animal

2. In which ways, and to what extent do representations associate with children's understanding?

A feature of the Lesh Translation Model is the movements within and between different modes of representation. Therefore, the findings are presented as 'pathways' for each child in the form of a diagram. The pathway of understanding for each child consists of (i) the movements within/between representation modes (using thin arrows); (ii) and prompts made by the researcher (P). The prompts by the researcher varied among the children; they included requesting the children to make translations, requesting them to explain mathematical ideas and thinking processes, and recommending them to overcome difficulties and troubles faced during problem-solving. 


\section{Aimy's Pathway of Understanding}

Aimy was given a simple problem involving two addends. As can be seen in Figure 6, Aimy began with creating drawings in her attempt to find the total number of legs. By manipulating her drawings, she successfully arrived at the total sum (as mentioned in the previous section: Figure 1). Noticing that Aimy had not attempted to check her answer using other forms of representation, the researcher prompted her to make a translation to another form of representation (i.e. concrete materials). By referring to her drawings carefully, Aimy managed to perform the translation between two different forms (i.e. from pictures to manipulatives - using cubes). Despite using different representation forms, she manipulated the cubes similarly as she had manipulated her drawings (i.e. constructed the quantities, prior to counting them to obtain the total).

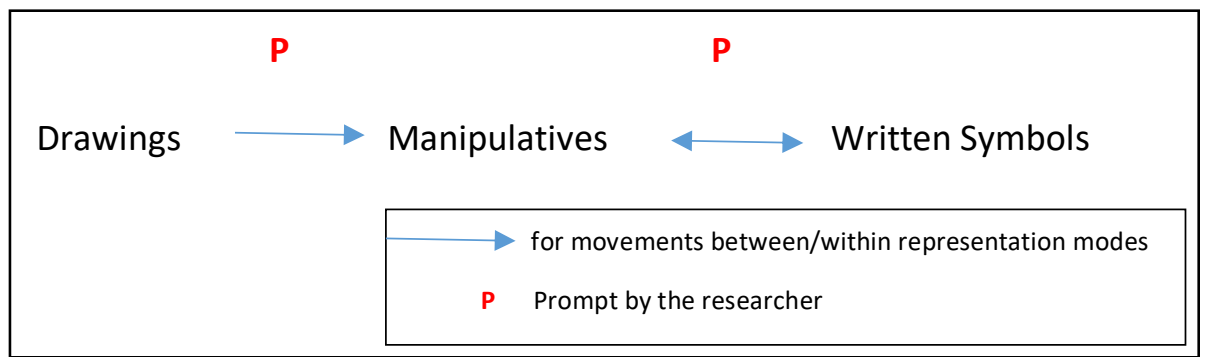

Figure 6: Aimy's pathway of understanding

When prompted to make the translation into symbols, Aimy referred to her coins (Figure 2) and counted them one by one each time before writing the corresponding numeral for each addend and the total. Her reference to the coins and as a reflection of her actions on them, permitted her to notice the link between the actions she had performed on the coins and the symbols she was to write. Hence, the connection that she made between the two forms of representation facilitated her in producing the complete number sentence (i.e. ' $4+4=8$ ').

\section{Norman's Pathway of Understanding}

Problem A which was given to Norman comprised of three animals (i.e. three addends). Hence, it required his understanding the addition of three sets or quantities. Figure 7 shows the pathway of Norman's understanding.

Initially, Norman chose Written Symbols (Figure 7) but found it difficult to continue presenting the legs for the third animal using symbols. Noticing his struggle, the researcher prompted him to switch to using another form of representation. As can be seen in Figure 5, Norman chose to use manipulatives (i.e. pegs). While he was attaching the corresponding number of pegs to the animals' pictures, he simultaneously verbalized 'four and four', suggesting that he spontaneously made the translation from manipulatives into Verbal Symbols. 
$\mathbf{P}$

Written Symbols $\rightarrow$ Manipulatives $\rightarrow$ Verbal Symbols $\rightarrow$ Symbols (in mind) $\rightarrow$ Written Symbols

$\rightarrow$ for movements between/within representation

modes

P Prompt by the researcher

Figure 7: Norman's pathway of understanding

At the same time, he might have depicted the quantities symbolically in his mind. Doing so permitted him to notice the addends as having the same quantities, so he instantly verbalized the double numbers 'four and four, eight'. He then verbalized the total sum of 'ten', immediately. The act of performing translations had allowed Norman's understanding to deepen; hence, it eased him to succeed in adding the three addends together. Equally important was that using multiple representations (i.e. concrete materials and symbols) had aided Norman to notice the properties of addition that in turn enabled him to arrive at the answer accurately and easily. He finally wrote his number sentence that contains the third addend.

\section{Discussion of Findings}

The Lesh Translation Model (i.e. within, and between representations) has enabled the diagramming of the children's pathways in their mathematical actions as they were involved in the addition process while solving the posed problems. The discussion of the findings presented in this article, as the children's pathways of understanding, is organized into two main themes: (i) the lack of spontaneity in using multiple representations; and (ii) the children's struggles in performing translation into symbols.

The lack of spontaneity in using multiple representations

This study found that both children utilized multiple representations in attempting the addition problems, however, they did not automatically perform meaningful translations within, and between the representation forms. Despite the fact that they managed to select their own initial representation themselves (presumably their 'preferred' representation form), both children required encouragement and only began to use a different form of representation after being prompted by the researcher. Notwithstanding being offered to use multiple forms of representation, Aimy used only drawings to solve the given problem. This provided evidence for her lack of spontaneity in utilizing different forms of representation. Hence, although offered the freedom and opportunity to use a variety of representation forms, there was no guarantee that the children would profit from the opportunities presented to them. As Davis (1984) contended, students are capable of discovering mathematical relationships when given the opportunities to explore and experience mathematical situations and ideas. 
Nevertheless, the findings reported in this study proved that providing opportunities alone does not enable the automatic discovery of relationships among different representations. In fact, children require more than just encouragement; for instance, prompts from the teacher need to be flexible when using representation during mathematical tasks. As observed in this study, only after being requested by the researcher to make translations (i.e. into concrete and symbolic forms) that Aimy used concrete materials and wrote the addition equation.

Children often feel satisfied after having arrived at a problem's solution using a particular representation form. This may probably clarify their lack of spontaneity in utilizing multiple forms of representation. As they successfully obtain an answer to a problem, they feel that it is no longer important to employ other forms of representation, even if they are unsure whether the answer is correct or not. In this study, both children offered their answers as soon as they found the sum, and did not attempt to use other forms of representation to check for the total previously obtained.

\section{Struggles in Performing Translation into Symbols}

This study exhibited that making a translation into symbols (mainly for the addition involving three addends) appears to have created a great challenge for most of the children in this study. One child found it troublesome to compose the addition equation completely. The child seemed to have struggled to include either the quantity of the third addend or the ' + ' sign in the number sentences produced. This shows that children are able to achieve only partial translation (Ainsworth, Prain, \& Tytler, 2011), by performing translation that contains only a portion of data from a stated problem. Although children may successfully arrive at the solutions and perform translations (e.g. concrete materials and drawings), they may find it difficult to write a complete and correct number sentence (Anghileri, 1995; Shiakalli \& Gagatsis, 2006). This provides evidence that children are capable of making translations for quantities of objects but not the relationship among objects. They are able to make translations for the quantities of objects into symbols because numerical symbols are understood more quickly by children than written arithmetic equations (Zhou, Wang, Wang \& Wang, 2006). Furthermore, children's capability to map between symbolic and non-symbolic representation occurs at around the time they master the counting system (Lipton \& Spelke, 2005).

In addition, viewing addition as a unary operation (Baroody, Wilkins, \& Tiilikainen, 2003) possibly offers an alternative explanation for the children's understanding of addition that convinces them to construct incomplete number sentences and equations. Since children lack the experience, their understanding of addition probably commences with a set of objects (or numerals), to which another group of objects (or numerals) is added. Should the children have adequate experience with addition, specifically in operations with more than two addends, they might be able to recognize addition as binary operations and might be able to write complete and correct addition equations. As emphasized by Baroody et al. (2003), students initially view addition as a unary operation, before 
being able to perceive it as a binary operation. Therefore, providing richer situations and experience in addition is beneficial for a deeper understanding of addition.

\section{Conclusion, Implication and Recommendations}

Using the Lesh's Model to diagram children's mathematical activity while they were solving posed problems revealed relationships between representation and depth of understanding. The different pathways diagrammed for each child illustrated the unique means in which a child progressed towards building understanding. The differences were mainly determined by each child's preference for representational forms. The findings of this study showed that the depth of mathematical understanding imposes the integration of different representation forms and flexibility in utilizing those various forms. Thus, a deep mathematical understanding may be achieved by the children should each of them make meaningful relationships between and within representations (translations).

Since children lack experience in solving problems, they depend heavily on encouragements and prompts by the 'teacher' prior to exploring and experiencing the use and benefits of other representation forms that differ from their preferred representation. This study's implications for teachers highlight that instruction should consist of appropriate monitoring during problem-solving practices. Most importantly, teachers should emphasize on the appreciation of the usage of multiple representations and empower children to select representations that are meaningful to them as a starting point of development.

Clearly, exploring children's use of representation in problem-solving is amongst the best means to stimulate their thinking processes. This owes to the fact that children's use of representation in solving problems reflects numerous facets of their mathematical thinking. This permits teachers/researchers to infer the children's progress in understanding mathematics, as revealed by the pathways that the children traverse while engaging in problem-solving. Future study is recommended to research and document this approach from a "quantitative" point of view that includes a greater number of students as well as examining other interesting mathematics topics such as subtraction operation and spatial sense. Additionally, it is suggested that future research includes the examination of teachers' use of multiple representations, as well as their fluency in performing translation within, and between representation forms during teaching/instruction. Teachers' practice in the classroom is essential in influencing how students can become flexible in using different representation forms and in performing fluid translations within, and between representations. Consequently, teachers' relentless efforts may affect the extent and quality of mathematical understanding among students.

\section{Acknowledgment}

This research was supported by grants provided by the Faculty of Education, Universiti Kebangsaan Malaysia (GG-2019-061) and (GG-2019-011). 


\section{References}

Abdullah, N., Halim, L., \& Zakaria, E. (2014). VStops: A thinking strategy and visual representation approach in mathematical word problem solving toward enhancing STEM literacy. Eurasia Journal of Mathematics, Science \& Technology Education, 10(3), 165-174.

Abdullah, N., Zakaria, E., \& Halim, L. (2012). The effect of a thinking strategy approach through visual representation on achievement and conceptual understanding in solving mathematical word problems. Asian Social Science, 8(16), 30-37.

Ahmad, A., Tarmizi, R. A., \& Nawawi, M. (2010). Visual representations in mathematical word problem solving among form four students in Malacca. Procedia-Social and Behavioral Sciences, 8, 356-361.

Ainsworth, S., Bibby, P., \& Wood, D. (2002). Examining the effects of different multiple representational systems in learning primary mathematics. The Journal of the Learning Sciences, 11(1), 25-61.

Ainsworth, S., Prain, V., \& Tytler, R. (2011). Drawing to learn in science. Science, 333(6046), 1096-1097.

Anghileri, J. (1995). Children's mathematical thinking in the primary years. Perspectives on Children's Learning. New York: Cassell.

Ayub, A., Ghazali, M., \& Othman, A. R. (2013). Preschool children's understanding of numbers from multiple representation perspective. IOSR Journal of humanities and social science, 6, 93-100.

Bakar, K. A., \& Karim, A. A. (2019). Young Children's Photographs of Addition in the School Environment. International Journal of Academic Research in Business and Social Sciences, 9(8), 1-14.

Baroody, A. J., Wilkins, J. L., \& Tiilikainen, S. H. (2003). The development of children's understanding of additive commutativity: From protoquantitive concept to general concept? In A. J. Baroody \& A. Dowker (Eds.), The development of arithmetic concepts and skills: Constructing adaptive expertise (pp. 127-160). Mahwah, NJ: Erlbaum.

Bautista, A., Habib, M., Ong, R., Eng, A., \& Bull, R. (2019). Multiple Representations in Preschool Numeracy: Teaching a Lesson on More-or-Less. Asia-Pacific Journal of Research in Early Childhood Education, 13(2).

Chigeza, P. (2013). Translating between and within representations: Mathematics as lived experiences and interactions. Paper presented at the Annual Meeting of the Mathematics Education Research Group of Australasia (MERGA, 36th, Melbourne, Victoria, Australia, 2013).

Davis, R. B. (1984). Learning Mathematics. The Cognitive Science Approach to Mathematics Education, Ablex, New Jersey.

Diezmann, C., \& English, L. (2001). The roles of representation in school Mathematics: 2001 Year Book. Virginia: NCTM.

Elia, I., Gagatsis, A., \& Demetriou, A. (2007). The effects of different modes of representation on the solution of one-step additive problems. Learning and Instruction, 17(6), 658-672.

Francis, F., \& Tom, R. (2001). Representation: An important process for teaching and learning mathematics. Teaching Children Mathematics, 7(5), 288.

Gagatsis, A., \& Shiakalli, M. (2004). Ability to translate from one representation of the concept of function to another and mathematical problem-solving. Educational Psychology, 24(5), 645-657. doi:10.1080/0144341042000262953 
Goldin, G. (1998). Representational systems, learning, and problem-solving in mathematics. Journal of Mathematical Behavior, 17(2), 137-165. doi:10.1016/S03640213(99)80056-1

Goldin, G., \& Shteingold, N. (2001). Systems of representations and the development of mathematical concepts. In A.A. Cuoco \& F.R. Curcio (Eds.), The roles of representation in school mathematics (pp 1-23). Reston, VA: NCTM

Hiebert, J. (1997). Making sense: Teaching and learning mathematics with understanding. Portsmouth, NH: Heinemann.

Kaur, D., Koval, A., \& Chaney, H. (2017). Potential of using iPad as a supplement to teach math to students with learning disabilities. International Journal of Research in Education and Science, 3(1), 114-121.

Lesh, R., Post, T., \& Behr, M. (1987). Representations and translations among representations in mathematics learning and problem-solving. In C. Janvier (Ed.), Problems of representation in the teaching and learning of mathematics (pp. 33-40). Hillsdale, NJ: Erlbaum.

Lipton, J. S., \& Spelke, E. S. (2005). Preschool children's mapping of number words to nonsymbolic numerosities. Child Development, 76(5), 978-988.

Mokwebu, D. J. (2013). An exploration of the growth in mathematical understanding of grade 10 learners. Retrieved from http://hdl.handle.net/10386/1110

NCTM. (2000). National Council of Teachers of Mathematics, Principles and Standards for school mathematics. Reston, VA: National Council of Teachers of Mathematics.

Papadakis, S., Kalogiannakis, M., \& Zaranis, N. (2017). Improving mathematics teaching in kindergarten with realistic mathematical education. Early Childhood Education Journal, 45(3), 369-378.

Pape, S. J., \& Tchoshanov, M. A. (2001). The role of representation (s) in developing mathematical understanding. Theory into Practice, 40(2), 118-127.

Rosli, R., Goldsby, D., \& Capraro, M. M. (2015). Using Manipulatives in Solving and Posing Mathematical Problems. Creative Education, 6(16), 1718.

Shiakalli, M., \& Gagatsis, A. (2006). Compartmentalization of representation in tasks related to addition and subtraction using the number line. In Novotná, J., Moraová, H., Krátká, M. \& Stehlíková, N. (Eds.). Proceedings of the 30th Conference of the International Group for the Psychology of Mathematics Education (pp. 105-112). Prague, Czech Republic: PME.

Suh, J., Johnston, C., Jamieson, S., \& Mills, M. (2008). Promoting decimal number sense and representational fluency. Mathematics Teaching in the Middle School, 14(1), 4450.

Tyng, K. S., Zaman, H. B., \& Ahmad, A. (2011). Visual application in multi-touch tabletop for mathematics learning: A preliminary study. Paper presented at the International Visual Informatics Conference (pp. 319-328), Springer, Berlin: Heidelberg.

Ulusoy, F., \& Incikabi, L. (2019). Incorporating Representation-Based Instruction into Mathematics Teaching: Engaging Middle Schoolers with Multiple Representations of Adding Fractions. In Handbook of Research on Promoting HigherOrder Skills and Global Competencies in Life and Work (pp. 311-336). IGI Global.

Yuanita, P., Zulnaidi, H., \& Zakaria, E. (2018). The effectiveness of Realistic Mathematics Education approach: The role of mathematical representation as mediator between mathematical belief and problem solving. PloS one, 13(9), e0204847.

Zhou, X., Wang, Y., Wang, L., \& Wang, B. (2006). Kindergarten children's representation and understanding of written number symbols. Early Child Development and Care, 176(1), 33-45. doi:10.1080/0300443042000302645 